\title{
Erythema Multiforme, CTCAE
}

National Cancer Institute

\section{Source}

National Cancer Institute. Erythema Multiforme, CT CAE. NCI Thesaurus. Code C143449.

A disorder characterized by targ et lesions (a pink-red ring around a pale center). 